\title{
INVESTIGACIONES ARQUEOLÓGICAS EN FLOR DEL MAYO, MOYOBAMBA, DEPARTAMENTO Y REGIÓN SAN MARTÍN. TEMPORADA 2014
}

\author{
Jorge E. T. Silva Sifuentes y Cecilia Jaime Tello
}

\section{RESUMEN}

Las investigaciones arqueológicas en Flor del Mayo confirmaron la ocurrencia de una antigua población asentada en la parte alta del actual caserío, donde registramos una estructura de piedras al pie de la colina. La alfarería sugiere una ubicación temporal en el período de Reinos y Confederaciones Tardíos o Intermedio tardío (+1300-1440 D.C.), así como vínculos con el señorío de Chachapoyas. Los rasgos de la cerámica se asemejan a las encontradas en el sitio de Chazuta de la región San Martín.

Palabras Clave: Moyobamba, Flor del Mayo, Alto Mayo, Arqueología, Inka, Tahuishco, cultura, excavaciones.

\section{ARCHAEOLOGICAL RESEARCH IN “FLOR DEL MAYO”, MOYOBAMBA, SAN MARTIN DEPARTMENT AND REGION. YEAR 2014}

\begin{abstract}
The archaeological investigations in Flor del Mayo town confirmed the existence of an ancient population settled on top of the present town, where there is a structure made of stones at the base of the hill. Recorded pottery remains suggest cultural links with Late Regional States or Late Intermediate Period (A. D. +1300-1440) and the kingdom of Chachapoyas. Also with occupations such as those of the Chazuta site.
\end{abstract}

KeYwoRDS: Moyobamba, Flor del Mayo, Upper Mayo, Archaeology, Inka, Tahuishco, Culture, Excavations. 


\section{Introducción}

M oyobamba, capital del departamento de San Martín, hoy Región San Martín, se halla en el Alto Mayo, en el nororiente peruano y en la vertiente de la cuenca amazónica, a $860 \mathrm{msnm}$. La zona es lluviosa y caliente $\left(27^{\circ} \mathrm{C}\right.$ en promedio) conocida por los nombres de rupa rupa, ceja de montaña o selva alta. Actualmente Moyobamba, considerando su casco urbano, alberga 49667 habitantes según datos del año 2012. En la actualidad la cifra asciende aproximadamente a 65 mil personas.

Moyobamba deriva de los vocablos quechua Muyupampa, que significa pampa circular o redonda; y Mayopampa que corresponde a río de la llanura. La fecha de su fundación española ha generado dudas por lo que en 1988 la Municipalidad Provincial de Moyobamba (1988) nombró una comisión integrada por los profesores moyobambinos Rosalina Villacorta Bustamante, Pedro Vargas Rojas, Ricardo López Perea y Carlos Noriega Bardález para revisar documentación sobre su fundador y cuándo. Esta comisión concluyó que el capitán Juan Pérez de Guevara la fundó con el nombre de Santiago de los Valles de Moyobamba el 25 de julio de 1540 (Resolución Municipal 208/88-MPM del 21 de diciembre de 1988 firmada por el entonces alcalde Rafael Bardález Cifuentes).

Se deduce que la fundación se produjo el 25 de julio, pues es el día del patrón Santiago y conforme a Vicente y Linci (1995: 165) la provisión de Francisco Pizarro disponiendo su fundación la firmó el 7 de junio de 1540, y probablemente a Juan Pérez de Guevara no le tomó más de un mes llegar a Moyobamba y fundarla precisamente en el día del patrón Santiago. Por otro lado, se deduce que fue el año de 1540 por una carta que el 13 de febrero de 1541 Francisco Pizarro envió a Juan Pérez quien estaba en Moyobamba (Municipalidad Provincial de Moyobamba 1988: 24; Vicente y Linci 1995: 165; para una discusión pormenorizada ver Espinoza 2003; ver también Mendoza 2014, Vargas 2013).

Según la provisión antedicha fue F. Pizarro quien propuso el nombre de Santiago, ordenando a su vez a Juan Pérez que descubra y conquiste Moyobamba nombrándolo Teniente de Gobernador y Capitán General. No mucho tiempo después y encontrándose el capitán Juan Pérez en Moyobamba fue informado del asesinato de Francisco Pizarro en Los Reyes el 26 de junio de 1541, debido a este hecho se unió a las fuerzas de Vaca de Castro y "mientras tanto quedó sin efecto la conquista y fundación de Moyobamba, apenas iniciada" (Vicente y Linci 1995: 165).

¿Qué pretendían los españoles al fundar una ciudad en el Alto Mayo? ¿Qué importancia tuvo el Alto Mayo en tiempos prehispánicos? Si bien la primera pregunta no se tratará aquí, brevemente puede decirse que su ubicación lo convertía en un punto de enlace entre la sierra y la selva, función que también ejerció antes de la presencia hispana en esta zona. En cuanto a la segunda pregunta, tema de este artículo, las poblaciones del Alto Mayo y Moyobamba por situarse a orillas del río Mayo o en sus proximidades tuvieron la ventaja de relacionarse con otras del Alto Huallaga y Chachapoyas. Si nos atenemos a lo manifestado por los cronistas, entre ellos Garcilaso de la Vega (1966), o Cieza de León (1979), solo para 


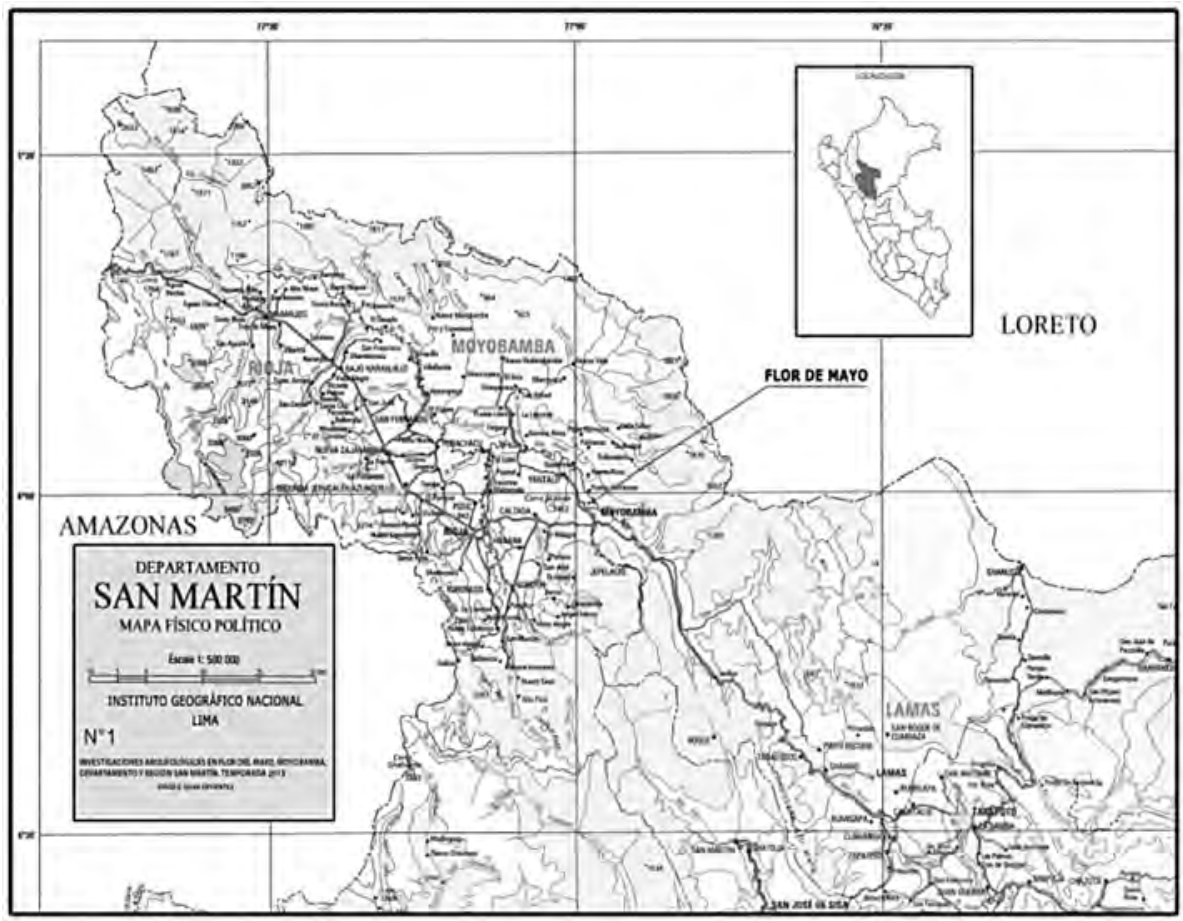

Mapa de la región San Martín y ubicación de área de estudio

mencionar dos fuentes, el Alto Mayo estuvo vinculado económicamente con el señorío de Chachapoyas en tiempos pre incas. Indican también que estos últimos conquistaron el reino de Chachapoyas hecho que repercutió en las poblaciones del Alto Mayo.

Mientras que unos cronistas señalan que las primeras entradas a Moyobamba la hizo Túpac Yupanqui, otros atribuyen a Huayna Cápac la conquista del Alto Mayo. Al respecto, a pesar que los documentos señalan que los incas incursionaron en esta zona, la arqueología aún no ha recogido datos suficientes sobre la presencia cusqueña en el Alto Mayo. Asimismo, los datos arqueológicos sugieren que la zona de Moyobamba estuvo habitada por sociedades neolíticas simples mostrando en algunos casos niveles de integración política tipo tribal cuya subsistencia dependería del cultivo de roza, recolección, caza menor y pesca.

Las primeras referencias sobre estas sociedades las recogió Alonso de Alvarado quien luego de fundar San Juan de La Frontera de Chachapoyas en setiembre de 1538 descendió hasta Moyobamba y derrotó a los nativos de esa zona, luego del cual ordenó a Juan de Rojas explorar los territorios adyacentes, quien retornó remarcando que no había riqueza alguna que valga la pena conquistar (Espinoza 2003:18). A partir de ese momento los españoles los Ilamaron "motilones" por llevar la cabeza rapada y los rostros pintados.

Nuestras investigaciones se realizan al norte de la ciudad de Moyobamba, cruzando el río Mayo, en la localidad de Flor del Mayo, en el Alto Mayo, sea con un bote a motor o una balsa cautiva en el puerto de Tahuishco y desembarcar en el Vergel antes de ascender 
ligeramente por un camino carrosable en dirección noreste. Este lugar fue hasta mediados de la década de 1970 un bosque natural primario compuesto por chonta, aguajales y grandes árboles propios de la región tales como el renaco, el ojé, guayabos, pacaes y guabas, además de naranjales que fueron introducidos desde tiempos de la colonia. Anteriormente hemos investigado la historia y etnohistoria de Lamas (Silva, Jaime 2005).

Hoy, Flor del Mayo es una zona que poco a poco se convierte en una pequeña población dedicada al cultivo de arroz, yuca, plátano, frutales (naranja, mandarina), y productos tipo hortaliza. La zona se halla al sur de una cadena de cerros en dirección oeste-este, paralela al curso del río, y a unos 8-10 km de la orilla norte del río. Se caracteriza por mostrar abundante vegetación y terreno ondulado con pequeñas colinas de baja elevación producto del acarreo natural procedente de los cerros antes mencionados.

Hasta la fecha es poco lo que se ha estudiado sobre la arqueología de Flor del Mayo y el Alto Mayo, incluyendo Moyobamba, a diferencia de la abundancia de datos que las crónicas y relatos ofrecen para esta zona. Entre las contribuciones sobre la arqueología de la zona aledaña a la provincia de Moyobamba figuran, entre otras, las de Bonavia (1968), Church (1996), Bueno (2009), Echevarría (2008), Rodríguez (2012), Lozano (2002), Van Dalen, Cornejo, Alarcón (2013), Mendoza (2001, 2009, 2014), Vargas (2013). Sin embargo, son las crónicas que señalan que Moyobamba, Flor del Mayo, y esta parte del Alto Mayo, estarían vinculados a pequeños grupos locales, entre ellos Tahuishco. Este y otros asentados en lo que hoy es Moyobamba y su entorno mantuvieron relaciones culturales con el señorío de Chachapoyas e incorporados, no se sabe si parcial o totalmente, al dominio inca en tiempos de Huayna Cápac (ver, entre otros, Cieza 1979, 1977, Garcilaso 1966, Betanzos 1992).

Por otro lado, en Flor del Mayo existe una construcción de piedras canteadas y rústicamente labradas compuesta por dos muros que forman un corredor o pasadizo de 1 $\mathrm{m}$ de ancho en promedio de más de $12 \mathrm{~m}$ de largo, orientado de noreste a suroeste y cerrado en su lado occidental, en dirección al río Mayo. Shimada planteó que se trataba de una construcción en forma de U del período Formativo (Shimada, Elera y Shimada 1982), por su parte Salazar, Silva y Burger (2015) propusieron una interpretación diferente con materiales de superficie recuperados a fines de la década de 1980.

Tomando en cuenta lo señalado, nuestra investigación se propuso recuperar información basada en excavaciones para aproximarse a las características culturales de los grupos asentados en Flor del Mayo y Moyobamba arribando, como se explicará más adelante, a resultados novedosos. Advertimos que lo presentado aquí es una versión preliminar.

\section{Objetivos y/o hipotesis}

Los objetivos se propusieron excavar unidades de prueba en Flor del Mayo para definir las características de la construcción llamada "El Túnel" y los restos culturales asociados a él, sobre todo en el sector de la Escuela de Educación Primaria. Igualmente, se identificó 
la estratificación cultural del citado sector y recogimos material cultural, sobre todo alfarería, que fue útil para aproximarse al o los grupos culturales de la zona y su antigüedad.

Para esta investigación partimos de la concepción desprendida de los documentos etnohistóricos según los cuales el Alto Mayo y la zona de Moyobamba fue ocupada por grupos pre-incas de organización sociopolítica simple poco entendida. Estos grupos establecieron relaciones en condiciones de subordinación con sus vecinos de Chachapoyas, al oeste, políticamente más avanzados, y luego de ser conquistados por los incas los grupos del Alto Mayo fueron indirectamente sometidos a la influencia cusqueña también.

\section{Método de campo y gabinete}

Los datos se recuperaron mediante excavaciones restringidas de $2 \mathrm{~m}$ por lado realizadas entre los meses de febrero y agosto del 2014. Se excavaron tres unidades, una en el noreste de la colina de la Escuela Primaria, en la sección Inicial o Jardín. Otra se localizó en la base occidental de la citada colina, concretamente adyacente a la estructura de grandes bloques de piedra llamada"El Túnel". Una tercera unidad de prueba se localizó en la parte superior de una colina natural situada inmediatamente al sur de la colina de la Escuela Primaria.

La excavación no identificó pisos, fogones o muros interiores, excepto por la arquitectura en superficie, pero permitió establecer la estratificación cultural y ubicar correctamente la procedencia de la cerámica, la misma que aparece en forma escasa. De ese modo se garantizó la clasificación de los restos alfareros secuencialmente, según el estrato, sobre todo en cuanto se refiere a sus atributos decorativos, morfológicos y tecnológicos. Este procedimiento, como se constatará en la sección correspondiente, resultó útil pues encontramos elementos decorativos comparables con los de otros asentamientos, como por ejemplo Chazuta.

El estudio en el gabinete puso atención a la cerámica y aunque no fue abundante fue importante por sus características o atributos de morfológicos, decorativos y tecnológicos, que sirvieron para definir preliminarmente el estilo cultural, su posible antigüedad, y hacer comparaciones con materiales de otros asentamientos.

\section{Resultados: sobre las excavaciones}

Flor del Mayo, Sector Escuela Primaria, sección noreste: Sección Inicial o Jardín. La unidad excavada recibió el número 3 y se localizó sobre una superficie con abundante maleza en declive sur-norte. Se registró 4 capas culturales que se profundizan unos $90 \mathrm{~cm}$ en promedio recuperándose solamente algunos fragmentos de cerámica. No se encontraron pisos o algo que sugiera un muro o un fogón. La capa 5 más profunda no contenía material cultural y se asentaba sobre el suelo natural o la roca madre. 


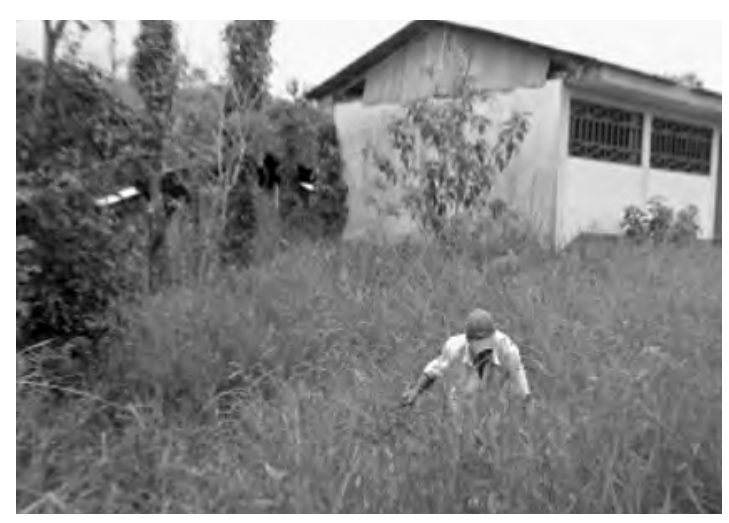

Unidad 3. Lado noreste de la Escuela Primaria de Flor del Mayo.

Flor del Mayo, Sector "El Túnel": Base oeste de loma de la Escuela Primaria. Este Sector destaca por presentar una construcción hecha con piedras grandes canteadas que forman un pasadizo orientado de noreste a suroeste de unos 10-12 m de longitud y encerrado en su lado occidental, denominado "El Túnel" por los pobladores. No fue posible determinar la base, solamente se despejó la maleza para fotografías e ilustraciones.

La Unidad recibió el número 4 y se identificaron cuatro estratos con contenido cultural, y una quinta más profunda sin material cultural, alcanzando en total $1.4 \mathrm{~m}$ de profundidad. Como en el caso anterior, excepto por la construcción "El Túnel" situada a $2 \mathrm{~m}$ al sur de la unidad de excavación, no se encontraron pisos, fogones o entierros. Solamente se recuperó cerámica en escasa cantidad aunque útil para tener una idea sobre el estilo cultural y para compararlo con otros asentamientos. Los restos alfareros de esta unidad proporcionan fundamentos preliminares para inferir la antigüedad de "El Túnel".

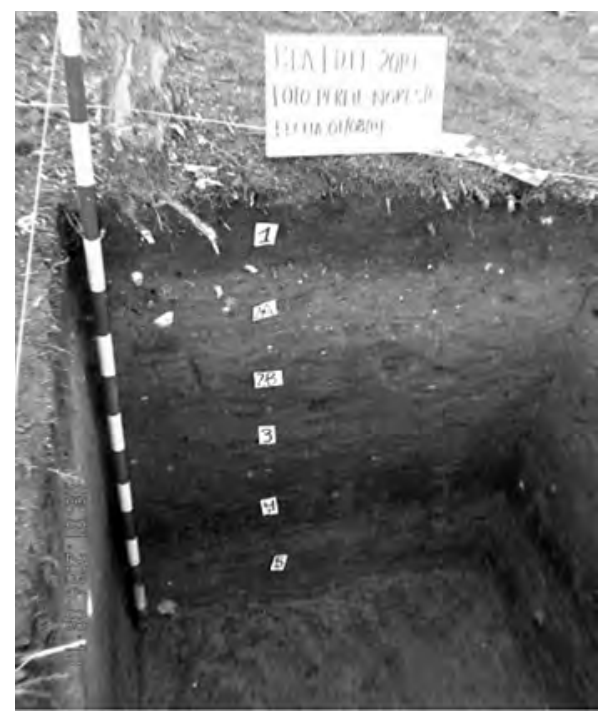

Flor del Mayo, "El Túnel". Unidad a 2 m al Norte de la estructura.

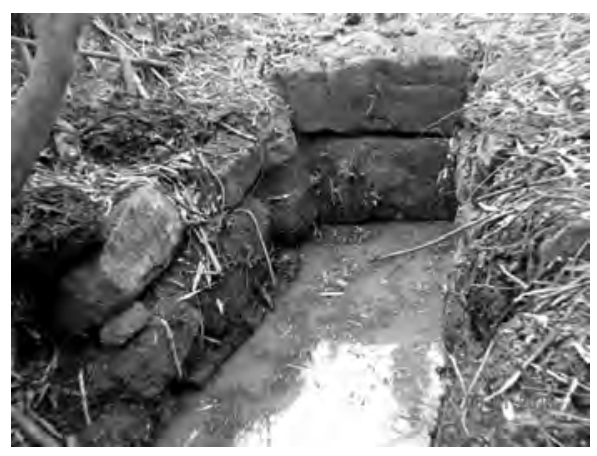

Flor del Mayo. "El Túnel". Tomado del este. 
Flor del Mayo. Excavaciones en el Sector Loma Neyra, al sur de la Escuela Primaria. Es una loma al sur de la loma de la Escuela Primaria y están separados por una depresión de $60 \mathrm{~m}$ con cultivos de arroz. El nombre Neyra hace referencia a la propiedad del sr. Jovino Neyra. Se identificaron tres capas, la primera es suelo agrícola, la segunda es arcillosa y la más profunda es la roca madre. La capa 2 tenía cerámica pero no se identificaron pisos o construcciones. El depósito cultural no tiene más de $30 \mathrm{~cm}$ de profundidad.

Loma Neyra. Unidad 1. Excavación de la capa 3. Roca madre.

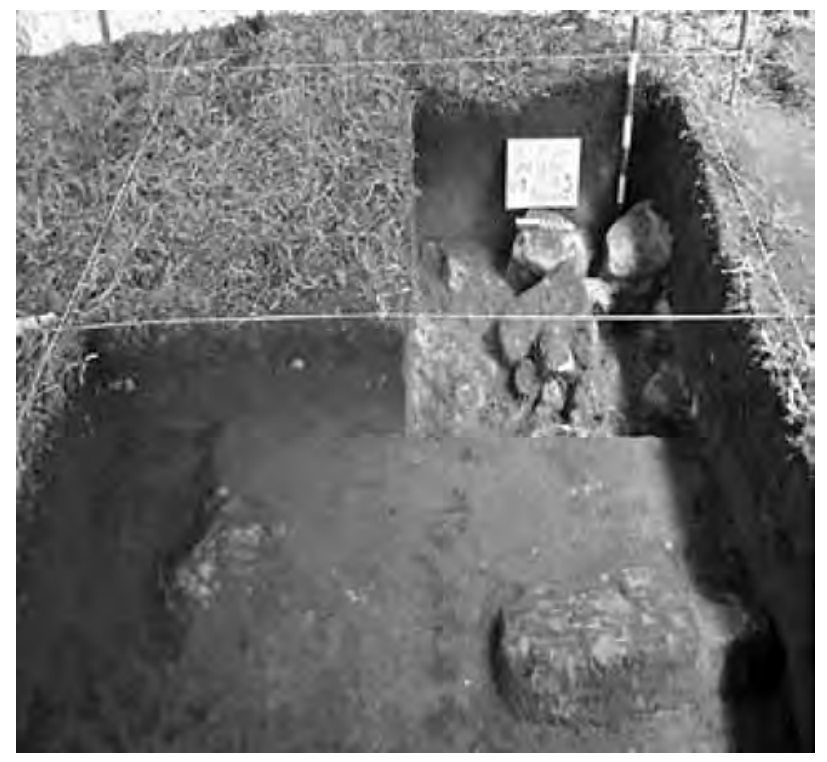

La arquitectura

La única evidencia de arquitectura corresponde al ya mencionado corredor o pasadizo llamado "El Túnel". Se trata de parte de una construcción cuyas piedras fueron canteadas sin mostrar acabado o labrado de tamaños distintos colocados de manera ordenada, dejando un aparejo uniforme que debido a las inclemencias del clima y el paso del tiempo perdió su suave apariencia. Se presume que este corredor fue parte de una estructura mayor de función aún desconocida. Si fue construida por los habitantes que se asentaron en esta zona en tiempos anteriores a la llegada de incas, o si fue resultado de la presencia cusqueña en Moyobamba tal como lo indican las crónicas, son interrogantes que aún deben estudiarse y aclararse.

La cerámica

La cerámica incluye no más de 500 fragmentos y procede de las capas 2 y 3, con menor incidencia en la capa 4, e inexistentes en la 5, en todas las unidades. Por otro lado, el alfar comparte características a través de todas las capas de manera que la cerámica muestra 
homogeneidad en sus atributos tecnológicos, morfológicos y decorativos sugiriendo que se trata de una unidad cultural o una cultura en particular. Por otro lado, debido a las Iluvias frecuentes los restos recuperados fueron tiestos, muchos en pésimas condiciones de conservación tanto en la decoración, como el acabado de sus superficies.

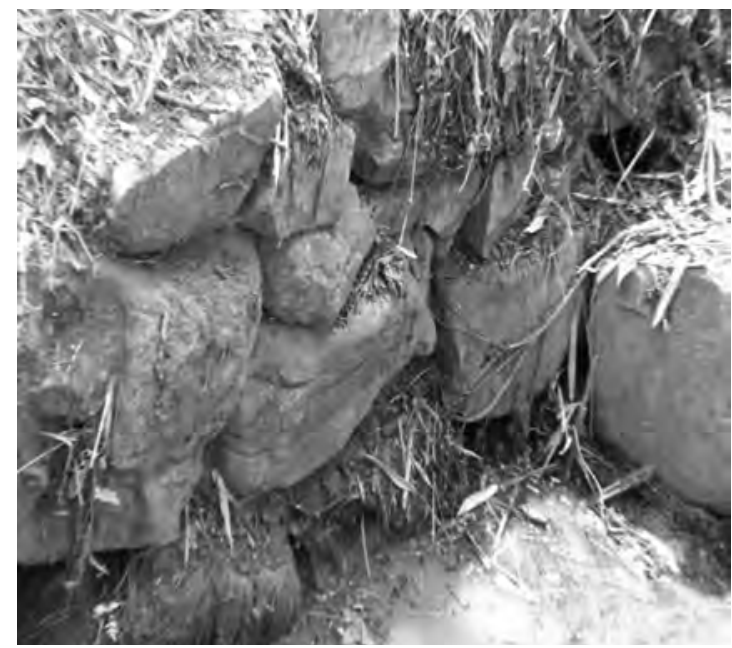

Flor del Mayo, Sector

"El Túnel". Unidad 4

situada a $2 \mathrm{~m}$.

\section{Tecnología}

Es generalizada la cocción incompleta, no controlada, por la existencia de pastas con núcleos grises y secciones claras de color rojizo amarillento (5YR 7/8, 7.5 YR 7/6, en la escala de color Munsell), rojo claro (2.5 YR 6/6) o marrón intenso (7.5 YR 5/8), gris claro (7.5 YR $\mathrm{N} 7 /$ ), u ocasionalmente rosáceo (5YR 7/8). En menor proporción aparecen tiestos cuyas pastas son grises o cocidas en atmósfera reductora u hornos cerrados.

Las superficies de los tiestos muestran acabados toscos y ásperos que en parte podrían deberse a la erosión natural por la humedad del ambiente. Los fragmentos que no están erosionados presentan superficies alisadas pero sin brillo u opacas, dejándose apreciar en la superficie partículas de contornos suaves que posiblemente fueron de la misma arcilla que no se mezclaron adecuadamente antes de modelar el recipiente. Entre esas partículas se observan también otras con aristas o aspecto irregular sugiriendo que parte de ellas fueron mordientes triturados previamente y agregados al momento de preparar la arcilla.

El contorno o las superficies de los recipientes no muestran uniformidad pues existen ligeras ondulaciones, o superficies sinuosas, a las que se suman huellas de estrías que quedaron al restregarse o nivelar la superficie pero sin intención de lograr superficies uniformes. El grosor de las pastas es variable, de $0.04 \mathrm{~mm}$ a $0.14 \mathrm{~mm}$, según el tipo de recipiente (cuenco, cántaro) o la parte del ceramio (las bases tienden a ser más gruesas que el cuello o la zona adyacente al borde del recipiente, o los bordes pueden ser ligeramente más gruesos que el cuerpo de la vasija). 
Finalmente, muchos tiestos muestran una delgada capa negra en el interior que se habría aplicado para proteger al recipiente, logrando impermeabilidad. En tal medida, esa sustancia tuvo carácter funcional antes que decorativo. Asimismo, esa sustancia oscura aún se utiliza para impermeabilizar recipientes de arcilla, o también en las separaciones y hendiduras de las embarcaciones de madera o canoas.

\section{Formas de vasijas}

En lo concerniente a las formas de los recipientes y tomando en cuenta los bordes, tratamiento interior/exterior, abundan vasijas abiertas expresadas en cuencos o tazones decorados y sin decorar, bases de cántaros o jarras, posiblemente un fragmento de botella. Por ello, nos concentraremos en los cuencos y tazones considerando la forma de sus bordes y la inclinación de sus paredes. Las formas identificadas son:

Cuencos de cuerpo con paredes delgadas y divergentes: provienen de la capa 3 y ocasionalmente la 4 . Son relativamente profundos no logrando determinarse sus alturas. El vertedero varía entre 11 y $17 \mathrm{~cm}$ de diámetro, con un promedio de $14 \mathrm{~cm}$., y sus paredes tienen de 2 a $4 \mathrm{~cm}$ de grosor, sugiriendo que fueron frágiles y pequeños. Excepto por uno que mostraría decoración ranurada o acanaladura horizontal el resto no está decorado.

Cuencos de cuerpo globular con borde reforzado en el exterior: recuperados en su mayor parte en la capa 3. El borde reforzado se logró colocando una banda, o tira de refuerzo, de 0.10 a $0.13 \mathrm{~mm}$ de ancho dispuesta horizontalmente alrededor del borde. En unos casos esta banda fue adelgazada en dirección al labio formando un bisel externo. El cuerpo de las vasijas tiende a converger al interior sugiriendo ensanchamiento en la zona ecuatorial del recipiente. Posiblemente fueron un poco más grandes que la forma anterior pues el diámetro del vertedero varía de 15 a $20 \mathrm{~cm}$. No se identificó decoración en este grupo.

Cuencos de cuerpo con paredes gruesas y divergentes: Proceden de la capa 3 como en los anteriores casos y posiblemente fueron más profundos que los antes descritos. Las paredes son gruesas, de 0.06 a $0.10 \mathrm{~mm}$ de espesor, y los diámetros del vertedero varían de 16 a $20 \mathrm{~cm}$. Ninguna presenta decoración.

Botella: También de la capa 3 y corresponde a un fragmento erosionado y posiblemente fue parte de una botella cuyo diámetro del vertedero alcanzó $6 \mathrm{~cm}$. Las paredes son delgadas y se observan los antiplásticos en la superficie. No está decorado.

Bases: Se cuenta con dos ejemplares de la capa 3 y serían tazones grandes pues sus superficies no son tan ásperas como para que sean ollas o cántaros. En un caso existe una sustancia negra adherida en lo que sería el fondo del recipiente. No están decorados.

\section{Decoración}

Incluye trazos en el exterior, sobre todo en cuencos. Solo un caso lleva pintura roja (2.5YR 4/8) pero se desconoce la forma. La ausencia de pintura se debe a la humedad y las lluvias 
que diluyeron la pintura. La decoración comprende: aplicación exterior (o tira de arcilla) en el borde posiblemente pintado de rojo; surcos o ranuras paralelas en el exterior (o corrugado); bandas de arcilla paralelas siguiendo la circunferencia del recipiente.

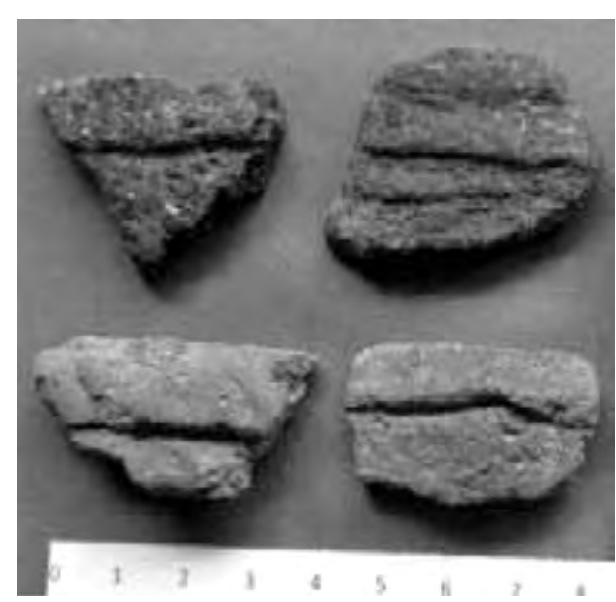

Flor del Mayo, "El Túnel". Capa 3. Bordes reforzados en el exterior. Superior derecho: Corrugado.

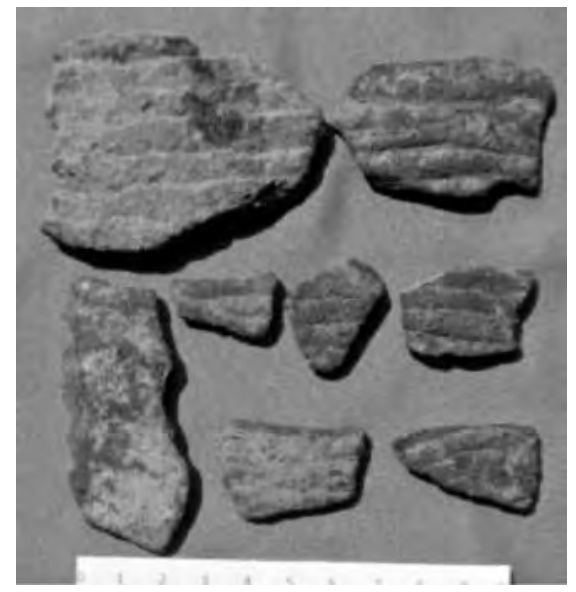

Flor del Mayo, "El Túnel". Capa 3. Decoración corrugada.

\section{Discusion y conclusiones preliminares}

Se divide en dos partes. La primera se referirá brevemente a los datos etnohistóricos sobre Moyobamba, sobre todo para examinar la problemática de los grupos nativos que encontraron los incas primero y los españoles después; asimismo, se abordará la situación de Moyobamba luego que fuera descubierta, explorada y fundada por los conquistadores. La segunda versará sobre los resultados de las investigaciones arqueológicas en la loma de la Escuela Primaria de Flor del Mayo y en la loma situada inmediatamente al sur de la antes indicada.

Más de un cronista se ha referido a Moyobamba y sus poblaciones nativas. Garcilaso de la Vega (1966) en el libro VIII de los Comentarios Reales de los Incas menciona dos tribus en el nororiente peruano, la de los Chachas o Chachapuyos, en el actual departamento de Amazonas, y Muyupampa, hoy Moyobamba, capital del departamento de San Martín, esta última menos importante que los Chachas. Menciona igualmente al grupo Chanca que se asentó en la zona tras ser derrotados por Pachacútec. De igual modo, en los capítulos I-III del citado libro VIII señala que los incas partieron de Llauntu (Levanto) para someter a los muyupampa quienes se incorporaron al constatar que los Chachapoyas se habían rendido. Garcilaso añade que los muyupampa se trasladaron a Huánuco aunque no se sabe si fue por voluntad propia o como parte de la política de remoción de poblaciones de su lugar original aplicado por los incas para evitar rebeliones. 
Pedro Cieza de León (1977) en el cap. 50 de su obra El Señorío de los Incas es más específico al señalar que los chancas se asentaron junto a una laguna bajo la guía de su líder Ancoallo tras la derrota sufrida ante los incas. Es de destacar que Cieza de León hace referencia a que un grupo de los chancas se estableció en Muyupampa (hoy Moyobamba) y otro en lo que hoy es Lamas. Antonio de Herrera en su crónica Décadas señala por su parte que la penetración Inca en el valle del Mayo fue obra de Túpac Yupanqui quien conquistó Chachapoyas, Moyopampa y Motilones en la década de 1440.

Tomando en cuenta estos datos se asume que en la zona entre Chachapoyas y el Alto Mayo habían dos grupos importantes: Chachapuyos en la hoy Chachapoyas, y grupos de Muyupampa en las actuales ciudades de Moyobamba y Rioja. Estos últimos habrían sido parte de una confederación con los chachapuyos en situación subordinada.

Las excavaciones de la temporada 2014 proporcionaron datos preliminares para empezar a responder algunas de las interrogantes planteadas por este proyecto. Por eso, considerando lo que se conoce estamos en la fase inicial sobre la arqueología de Moyobamba y del Alto Mayo y el entendimiento de sus antiguos pobladores basada en excavaciones estratigráficamente controladas. Para ello hemos priorizado las excavaciones en "El Túnel", que se halla en la sección oeste y en la base de la colina de la Escuela de Primaria de Flor del Mayo.

Si bien los resultados son preliminares, primero, se confirma la ocurrencia de una antigua población asentada en la parte alta de la lomada de la Escuela Primaria y en su base occidental, correspondiente a tiempos prehispánicos aun cuando no existe la convicción plena que la citada construcción sea de la época Inca, toda vez que en las excavaciones no se recuperaron tiestos de estilo Inca sea por su decoración o sus formas. Los decorados sugieren tener vínculos con el período que antecede a la época Inca, llamado Reinos y Confederaciones Tardíos (+1300-1440 D.C.), que se distinguen por cuencos con refuerzo exterior en el borde, y los ranurados o acanalados (Ilamados también corrugados) encontrados en otros sitios tales como Chazuta (Church 1996, Lozano 2002, Echevarría 2008).

Segundo, los restos de esa población están representados por (a) una estratificación cultural conteniendo cerámica fragmentada; (b) una construcción hecha con piedras canteadas y al parecer toscamente labradas que, como se indicó antes, está en la base occidental de la lomada de la Escuela y se trataría de una construcción más compleja. Por su apariencia monumental podría asignársele a tiempos incaicos, pero a la vez podría ser una construcción local. Si aceptamos que fue una construcción Inca asumiríamos tentativamente que los cusqueños ejercieron control indirecto de la zona, a través de alianzas con los grupos locales.

Por ello, presentamos a manera de una imagen borrosa, a la espera de nuevos datos que clarifiquen y confirmen nuestras presunciones preliminares, algunas ideas sobre el patrimonio arqueológico de Flor del Mayo. Es así que por ahora los datos etnohistóricos son el mejor sustento para asumir que en la zona de Moyobamba hubo una importante población local prehispánica organizada en comunidades autosuficientes cuyos nombres 
nativos además de Moyobamba todavía persisten, entre ellos Tahuishco, Marona, Posic, Oromina u Orimona.

Finalmente, si los relatos de los cronistas son correctos, en el sentido que los incas llegaron al Alto Mayo y a Moyobamba, entonces "El Túnel" de Flor del Mayo testificaría la presencia cusqueña en esta zona; pero, como se manifestó antes, no se recuperó cerámica Inca local, provincial o cusqueña en las excavaciones. De otro lado, si se verifica arqueológicamente esta proposición, derivaríamos otra hipótesis: la supuesta conquista Inca de Moyobamba respondería a su política expansiva a la selva siendo Moyobamba parte de la última frontera Inca en el nororiente peruano. Las excavaciones permitirán aproximarnos a despejar estos enunciados.

AgRAdeCIMIENTOS. Agradecemos el apoyo de las instituciones y las personas que nos permitieron llevar a cabo esta investigación: Ministerio de Cultura por el permiso de excavación, la Dirección Desconcentrada, sede Moyobamba, en la persona de su Sr. Director Lic. Luis A. Vásquez V., Profesor Balmes del Castillo, Director de la Escuela Primaria de Flor del Mayo, Lic. Lucy Chumbe Rodríguez Arqueóloga de la sede Moyobamba, Froilán Berru Neira propietario del predio en donde se encuentra El Túnel. A la Universidad Ricardo Palma por el apoyo económico para la temporada 2014. Asimismo, a Andrea Gonzáles Lombardi, Ricardo Guevara Tacoma, Andrea Gutiérrez Apaza, Winnie Martínez Sulca, Manuel Paredes Montero y Diego Rivera Gonzáles.

\section{Referencias bibliográficas}

Betanzos, J. (1992). Suma y Narración de los Incas. Madrid: Ediciones Atlas (transcripción, notas y prólogo de María del Carmen Martín Rubio).

BonAVIA, Duccio (1968). Las ruinas del Abiseo. Universidad Peruana de Ciencias y Tecnología. Lima. BUENO, A. (2009). Arqueología de la cuenca del río Guabayacu, región San Martín, Perú. Investigaciones Sociales 23, pp. 15-58. Revista del Instituto de Investigaciones Histórico Sociales, Facultad de Ciencias Sociales, Universidad Nacional Mayor de San Marcos. Lima.

CIEZA, P. (1979). Descubrimiento y conquista del Perú. Roma: Instituto Storico Italiano. Editada por Francesca Cantú.

CIEZA, P. (1977). El Señorío de los Incas. Lima: Editorial Universo, S.A.

CHURCH, Warren (1996). Prehistoric Cultural Development and Cultural Interaction in the Tropical Montane Forests of Peru. Ph. D. Thesis. Department of Anthropology, Yale University. University Microfilms, Ann Arbor.

ESPINOZA, W. (2003). Juan Pérez de Guevara y la historia de Moyobamba. Siglo XVI. Editora Magisterial Servicios Gráficos. Jesús María, Lima.

ECHEVARRíA, Gori (2008). Excavaciones Arqueológicas en Chazuta, San Martín. Un reporte de campo (Primera Temporada 2002). Amazonía Peruana, Tomo XV, № 31, pp. 323-341. 
GARCILASO DE LA VEGA, El Inca (1966). Royal Commentaries of the Incas and general history of Peru. Austin: University of Texas Press.

HeRRERA, Antonio de (1944). Historia general de los hechos de los castellanos en las islas y tierra firme del mar océano. Editorial Guarania, Asunción del Paraguay. Buenos Aires: Talleres Gráficos Continental.

LOZANO, A. (2002). Informe de la expedición multisectorial a la encañada de Tonchima. 6 y de mayo del 2002. Instituto Nacional de Cultura, Departamental San Martín, Moyobamba. 18 pp.

MendoZA, A. (2001). Los Aguaruna del Alto Mayo: El otro rostro del Perú. Moyobamba.

MENDOZA, A. (2009). San Martín: Historia, costumbre y sabiduría. Lima.

MendozA, A. (2014). Moyobamba. Ciudad Ancestral de la Amazonia. Moyobamba. Primera Edición.

Municipalidad Provincial de Moyobamba (1988). Reseña Histórica de la Fundación Española de Moyobamba. Municipalidad Provincial de Moyobamba (texto mimeografiado).

RodríGUeZ, M. (2012). Arte Rupestre en el departamento de San Martín. Gobierno Regional de San Martín. Lima: Editorial Super Gráfica E. I. R. L.

SAlAzAR, Lucy; SIlva, Jorge; Burger, Richard (2015). Flor de Mayo, Moyobamba, Perú; A formative u-shaped center in the Peruvian ceja de selva?. En Ñawpa Pacha, Volume 35, Number 1:91-116. Berkeley: Journal of Andean Archaeology, Institute of Andean Studies.

SHIMADA, Izumi, Carlos ElERA y Melody SHIMADA (1982). Excavaciones efectuadas en el centro ceremonial de Huaca Lucia-Cholope del Horizonte Temprano, Batan Grande, costa norte del Peru. Arqueológicas 19:109-210. Pueblo Libre, Lima.

SILVA, Jorge y Cecilia JaIme (2005). Alfarería tradicional de los lamas, Región de San Martín, Perú. En: El arte de vivir o la alegría sin límites de Félix Oliva. L. Millones y J. Villa, editores. pp. 137-160. Colección América. Fundación El Monte. Sevilla.

VICENTE, C., LINCI, J. (1995). Historia de Moyobamba. Revista del Archivo General de la Nación, Nº 12, Segunda Epoca, pp. 161-175. Lima: Archivo General de la Nación, Ministerio de Justicia.

Van Dalen, P., C. Cornejo, G. Alarcón. (2013). Arqueología de la Cuenca Media del Río Mayo, Moyobamba, San Martín. En Arqueología y Sociedad 26, pp. 207-228. Lima: Museo de Arqueología y Antropología, Centro Cultural de San Marcos, Universidad Nacional Mayor de San Marcos.

VARGAS, E. (2013). Historia de Moyobamba. Documental. Moyobamba. 
